\title{
Fenomenologia e geografia: teorias e reflexões
}

\section{Phenomenology and geography: theories and reflections}

Taiane Flores do Nascimento * Benhur Pinós da Costa**

\section{Resumo:}

$\mathrm{O}$ artigo tem como objetivo debater a proposta fenomenológica nas pesquisas referentes à ciência geográfica, bem como discutir diferentes formas de metodologias que a geografia pode introduzir em suas análises. Procura também ressaltar conceitos relacionados as abordagens fenomenológicas, relacionando com o espaço, que é uma categoria de análise fundamental da ciência geográfica. A abordagem teórica a partir dos autores é importante, pois a interpretação conceitual é a principal base de novas formulações e reformulações das ciências. Neste sentido, sabe-se que a fenomenologia é uma tendência forte dentro da perspectiva humanista, o que justifica a relevância dessa discussão.

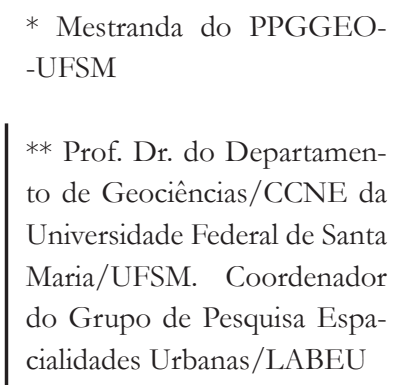

** Prof. Dr. do Departamento de Geociências/CCNE da Universidade Federal de Santa Maria/UFSM. Coordenador do Grupo de Pesquisa Espacialidades Urbanas/LABEU

\begin{abstract}
:
The article aims to discuss the proposed phenomenology in research pertaining to geographical science, as well as discussing different forms of methodologies that geography can introduce into their analysis. It also seeks to emphasize concepts related phenomenological approaches, relating to space, which is a category of critical analysis of geographical science. The theoretical approach from the authors is important because the conceptual interpretation is the main basis of new formulations and reformulations of science. In this sense, it is known that phenomenology is a strong tendency within the humanistic perspective, which explains the relevance of this discussion.
\end{abstract}

Palavras-chave:

Fenomenologia, Geografia, Espaço

Key-Words:

Phenomenology, Geography, Space 


\section{INTRODUÇÃO}

$\mathrm{O}$ presente artigo tem como foco central discutir a fenomenologia nas pesquisas referentes à Geografia, bem como analisar diferentes formas de metodologias na perspectiva das ciências sociais. Procura ressaltar conceitos relacionados as abordagens fenomenológicas, relacionando com o espaço, que é uma categoria de análise fundamental da ciência geográfica.

A proposta fenomenológica não é muito comum na geografia, e quem mais a tem discutido são pesquisadores da área cultural e humanística, pois procuram uma concepção de mundo que seja distinta da cartesiana e do positivismo. A Geografia Humanística aparece como tendência e apresenta novas formas de investigação ao pesquisador. Ela surge pela necessidade de inovações e diferentes problematizações que são postas no cotidiano, direcionando fatos geográficos mais significativos na atualidade e que exigem novas perspectivas de interpretação. Esta tendência, através da abordagem fenomenológica, tem como foco relacionar numa visão antropocêntrica do mundo, o homem e seu espaço ou, mais genericamente, o sujeito e o objeto. Ela vem para trabalhar com a experiência, ou seja, o espaço vivido e existencial do indivíduo, que serão considerados sobre diferentes perspectivas, principalmente os valores que o indivíduo adquire no cotidiano.

\section{DISCUSSÕES ACERCA DOS CONCEITOS}

A partir da premissa de que a abordagem fenomenológica não é fechada e não permite conclusões, é possível afirmar que a fenomenologia como método de análise ainda é um campo que há diferentes discussões e que está se solidificando cada vez mais com pesquisas que envolvem a geografia. Como ela é puramente percepção ou ainda intencionalidade, ou seja, de forma geral, é vista para muitos pesquisadores como uma forma de ocultar ou omitir especificidades que poderiam dar maior valorização em determinadas pesquisa. Neste sentido, incorporar a análise fenomenológica, tem sido particular de cada pesquisador em sua área de pesquisa no que se refere a suporte metodológico, ou ainda, para subsidiar determinada investigação no campo não só da ciência geográfica, mas nas ciências humanas.

Na geografia é possível perceber, em sua cronologia epistemológica, a evolução de seu pensamento coligado ao desenvolvimento da história da ciência no geral. E para entender um pouco mais sobre a evolução do leque de pesquisa da geografia, destacam-se algumas pontuações que delimitam as novas perspectivas de abordagem sobre o espaço.

A revolução qualitativa envolvendo questões sociais, dentro da perspectiva geográfica, se deu a partir de 1970 com a Geografia Crítica, onde absorveu grandes paradigmas contextuais marxistas. Neste período, a preocupação com a subjetividade do homem abriu possibilidades, mesmo que limitadas, como subsídio para estudos do espaço vivido. Sobre a relação da Geografia com a categoria de espaço vivido, destaca Gomes(1996, p.320):

A ciência geográfica, definida pelo viés do espaço vivido, não tenta criar leis, nem observar regularidades generalizadoras. Seu ponto de partida é, ao contrário, a singularidade e a individualidade dos espaços estudados. Ela também não procura avançar resultados prospectivos e normativos, como as ciências ditas racionalistas. Seu objetivo principal é fornecer um quadro interpretativo às realidades vividas espacialmente. A objetividade não provém de regras estritas de observação, mas do uso possível das diversas interpretações na compreensão do comportamento social dos atores no espaço.

Considera-se que a característica cartesiana baseia-se no questionamento metódico e atribui apenas às ciências naturais o que é racional e objetivo. Diz ainda, que apenas conceitos relativos a quantitatividade, são objetivos, atribuindo o que é racional a física e principalmente à matemática ${ }^{1}$. Para a fenomenologia, a razão objetiva se refere a existência humana, não dependendo de quantidade.

Não obstante, a própria revelação filosófica da concepção fenomenológica se aproxima da natureza epistemológica da ciência geográfica, pois os primeiros estudos relacionados à Geografia, a percepção e a essência de cada lugar eram os principais objetos de estudo. Desde o séc XVII - XVII, mesmo timidamente, a fenomenologia ocultada pelo positivismo, estava engajada nas pesquisas e principalmente no trabalho de campo. A principal diferença entre a análise temporal eram os estudos que envolviam a percepção. Primeiramente era considerada apenas a paisagem, os aspectos físicos dos lugares e isso resultava na diferenciação de áreas regionais. Já na terceira geografia ${ }^{2}$, onde os estudos estão atrelados até os dias de hoje, a percepção está no indivíduo que modifica essa paisagem. É nele que a fenomenologia consegue se sustentar em seus estudos.

O conceito de fenomenologia ganha destaque com Edmund Husserl, um filósofo contemporâneo. 
Husserl descreve de modo geral, a forma como as coisas se manifestam na consciência e que permite alcançar a essência dos fenômenos, incorporando experiências subjetivas, considerando além das impressões sensíveis e aparentes das ciências naturais. Para Suertegaray (2005, p. 29),

A fenomenologia de Husserl, segundo Chauí, vem de encontro às visões de Kant e de Hegel, para ele tudo que existe é fenômeno, só existem fenômenos. Portanto, consciência possui uma essência diferente da essência dos fenômenos, pois ela dá sentido as coisas e essas recebem sentido. Fenômeno, então, é consciência de... Tudo é fenômeno enquanto consciência de...

Resumindo, a consciência é sempre consciência de alguma coisa e a intencionalidade é o direcionamento da consciência a um objeto ou ação.

Sobre o que é fenomenologia, destaca-se Sokolowski (2004, p. 17):

A doutrina nuclear da fenomenologia é o ensinamento de que cada ato de consciência que nós realizamos, cada experiência que nós temos, é intencional: é essencialmente "consciência de" ou uma "experiência de" algo ou de outrem. Toda nossa consciência está direcionada a objetos. [...] Cada ato de consciência, cada experiência é correlata com um objeto. Cada intenção tem seu objeto intencionado.

Neste sentido, o autor diz que na fenomenologia, esta intenção significaria a relação de consciência que o indivíduo tem com o objeto, ou seja, ela reconhece a realidade e a verdade de determinados fenômenos, as coisas como elas aparecem a quem as observa. As coisas não apenas existem, mas também se manifestam a si mesmas como o que elas são. A paisagem é um exemplo clássico desta análise, pois ela tem um modo de se manifestar diferentemente no espaço. Descrições como estas, ajudam o indivíduo a entender ainda mais o conhecimento humano em todas as suas formas e formalidades, e também ajuda a compreender os diferentes modos em que se pode estar relacionado ao mundo em que se vive, ou ainda, em que o sujeito faz parte.

No campo da fenomenologia como método de abordagem, são os sujeitos que determinam o objeto, pois ela parte do pressuposto de que os sujeitos constituem a realidade, que é singular do próprio sujeito. Essa é uma possibilidade metodológica muito acessada pelas ciências humanas, e dentro da geografia a fenomenologia chega à categoria da percepção, ou seja, a percepção do indivíduo em seu entorno, destacando sua subjetividade. Neste sentido, pode-se dizer que os sujeitos determinam o objeto e os objetos constituem os sujeitos.

Para tanto, o objetivo do método fenomenológico é descrever a estrutura integral da experiência vivida, os significados que essa experiência tem para os indivíduos que a vivenciam. Em contrapartida ao positivismo, que pretende descobrir causas e estabelecer leis, a fenomenologia utiliza a observação para apresentar os dados/ informações como se apresentam.

Apesar de a geografia ter reflexões de significado filosófico, ainda carece de um debate maior com ênfase na geograficidade do ser no mundo contemporâneo e consequentemente a sua intencionalidade espacial. Uma das formas que tem sido buscada para preencher as aberturas é o diálogo mais estreito com o pensamento de alguns filósofos que, mesmo sem terem dedicado atenção específica à ciência geográfica, ocuparam-se, no campo da ontologia fenomenológica, com os problemas relativos ao homem e o espaço. Sobre a questão fenomenológica do ser no mundo, Sokolowski (2004, p. 53) faz uma observação:

O mundo como um todo e o eu como centro são as duas singularidades entre as quais todas as outras coisas podem ser colocadas. O mundo e o eu são correlatos um com o outro de um modo diferente daquele no qual uma intencionalidade particular é correlata com as coisas que intenciona. $\mathrm{O}$ mundo e o ego proveem um duo fundamental, um contexto elíptico para tudo.

Sokolowski apresenta em suas palavras o dualismo que é a base da fenomenologia: o sujeito pertencente ao mundo e o mundo pertencente ao sujeito. Considera-se então que, o mundo é uma configuração última para o indivíduo e para todas as coisas que ele experiência. Ele sempre será concreto e atual de experiências. O espaço neste sentido é dinâmico e faz parte da subjetividade do sujeito.

Martin Heidegger (2009), filósofo contemporâneo, em suas obras não evidenciava a geografia de fato, porém já atribuía em seus estudos, o espaço e sua relação com o homem, ou ainda, ressaltou a existência fundada no habitar. Este é a própria expressão da espacialidade do ser, enquanto forma de ser-e-estar-no-mundo, onde a fenomenologia é descrita em suas bases.

John Pickles (1985), grande leitor de Heidegger sobre a questão fenomenológica, diz que o questionamento ontológico é o fundamento mais importante do pensamento fenomenológico para a ciência geográfica, constituindo-se, como maior subsídio às ciências humanas, situando a geografia como a ciência do espaço. 
As proposições de Heidegger foram e ainda são importantes na Geografia Humanística estadunidense, onde mesmo timidamente, demonstram parcialmente as implicações da ontologia geográfica, porém suas maiores obras ficaram em francês e inglês, sendo pouco utilizadas como embasamentos teóricos no que tange a fenomenologia dentro da categoria de espaço, ou mais precisamente de lugar. $\mathrm{O}$ autor ainda auxilia a abrir novas perspectivas sobre a questão do "ser" na sociedade contemporânea, em sua geograficidade, que se manifesta no "lugar", enquanto fenômeno geográfico vivido e experienciado pelo sujeito, que dá sentido ao espaço que habita ou que viveu. Sobre o espaço, Heidegger (2009, p.168) comenta:

[...] o espaço só pode ser concebido recorrendo-se ao mundo. Não se tem acesso ao espaço, de modo exclusivo ou primordial, através da desmundanização do mundo circundante. A espacialidade só pode ser descoberta a partir do mundo e isso de tal maneira que o próprio espaço se mostra também um constitutivo do mundo, de acordo com a espacialidade essencial da presença, no que respeita à sua constituição fundamental de ser-no-mundo.

Neste mapeamento sobre a fenomenologia, ressaltam-se outros autores da ciência filosófica que contribuíram para a evolução do conceito de fenomenologia. Destacam-se além de Edmundo Husserl, as considerações importantes feitas pelo filósofo francês Maurice Merleau-Ponty, que teve grande influência pelas obras de Husserl.

Para Merleau-Ponty (1999, p.01), o conceito de fenomenologia,

[...] é o estudo das essências: a essência da percepção, essência da consciência, por exemplo. Mas a fenomenologia é também uma filosofia que repõe as essências na existência, e não pensa que se possa compreender o homem e o mundo de outra maneira se não a partir de sua "facticidade". [...] É a ambição de uma filosofia que seja uma "ciência exata", mas é também um relato do espaço, do tempo, do mundo vivido. É a tentativa de uma descrição direta de nossa experiência, tal como ela é e sem nenhuma referência à sua gênese psicológica e as suas explicações causais [...] que dela possam fornecer.

Neste sentido, já há uma relação entre o homem e o espaço vivido, que pode-se transferir para uma análise socioespacial. É neste enfoque teórico-metodológico que se permite entender o relato do mundo vivido, no espaço e no tempo, descrevendo-se, a experiência humana tal como ela é ressaltando a subjetividade do indivíduo.

A fenomenologia de modo geral, busca evidenciar as essências repondo-as na existência, na medida em que o concreto sempre existiu "ali", numa forma anterior ao pensamento. A abstração intelectual espaço-temporal do mundo "vivido" materializou-se no exercício descritivo da experiência da maneira como ela ocorre, uma vez que o real deve ser registrado e não construído ou constituído (MERLEAU-PONTY, 1999). Neste sentido, a experiência que constrói o mundo vivido e ele aparece como é observado pelo próprio sujeito.

Nas considerações de Alfred Schutz sobre a intencionalidade fenomenológica, destaca-se a fenomenologia do mundo social. Segundo Schutz (1979), Husserl aponta a vida cotidiana como um espaço da vida natural, ou seja, um espaço onde as pessoas se relacionam com os objetos as quais a intencionalidade está alcançando-as. Schutz ressalta ainda que a importância do significado é dada pela experiência passada que a pessoa possui sobre um fato. Quando o autor fala em fenomenologia do mundo social, instrumenta para as ciências sociais o método husserliano com o objetivo de compreender os mecanismos e de identificar as práticas e os significados sociais e subjetivos que os indivíduos manifestam nas interações cotidianas. As noções de contexto, de ação, de convivência e de interação passam a ser importantes à investigação dos rituais, dos imponderáveis e das racionalidades subjacentes à vida cotidiana dos indivíduos.

As pontuações de Schutz são importantes para a ciência geográfica, quando associa experiência, interações sociais com o mundo vivido. Neste contexto, faz-se um salto na evolução do conceito fenomenológico, atraindo para a ligação com o espaço, que é objeto de estudo da Geografia. A realidade social é produto de interações, da adição de objetos e fatos da vida cultural e social que o senso comum experiencia nas interações. São esses grupos sociais que produzem espaços, os quais são importantes para as análises geográficas.

As análises da fenomenologia na geografia humana têm diferentes abordagens no que se refere ao espaço vivido do indivíduo. Nesta perspectiva, Sokolowski (2004, p. 165) ao introduzir a fenomenologia, diz que:

A língua falada, os gestos intencionais e a linguagem corporal
imponderável são todos mais do que apenas movimentos cor-
porais; sinalizam atos intencionais, e também expressam con-
teúdo do pensamento. Expressam para nós como o mundo e
as coisas nele aprecem ser para alguém que está naquele corpo.
Se a outra pessoa emitir certos sons ou fizer certas caretas, po-
demos dizer que "lá vêm problemas" ou "não nos abandone
agora".

Considera-se na fala do autor, que os elementos importantes na construção do sujeito são visualizados dentro 
das expressões que o individuo apresenta em determinado espaço ou interação com outro individuo. Percebe-se desta forma, que a fenomenologia em primeiro momento está atrelada aos estudos culturais dentro da geografia. A cultura como forma de identificação social, pode ser restringida apenas aos valores que cada grupo ou etnia tem e é por essas questões que estudos envolvendo novos grupos sociais vêm se desenvolvendo dentro da geografia, com ênfase nas interações humanas.

Um grupo de fiéis de uma determinada religião, por exemplo, evangélica, que vem se destacando pelo crescente número de seguidores, pode ser considerado um grupo social que produz, organiza ou reorganiza o espaço. São indivíduos que possuem sua própria linguagem, modo de vestir, crenças e valores que os diferenciam de outro grupo religioso.

O grupo social travesti também é um exemplo concreto de uma sociedade construtora de espaços. Sabe-se que as travestis (no feminino, pois é assim que elas gostam de serem enunciadas) é um grupo social recluso de certos espaços. Elas se destacam no modo de se vestir, no modo de como se comunicam e principalmente no modo em que vivem. Estas expressões de gênero e sexualidade se dão pelos movimentos corporais, em determinados momentos com algo grau de afetividade, estes simbólicos, que as diferenciam enquanto ser social. Aliando afetividade e corporeidade com o interacionismo, chegam-se as relações sociais destes indivíduos em determinados espaços, que só se dão a partir da interação e possivelmente em expressões que apenas eles conseguem entender. A corporeidade neste sentido refere-se ao campo existencial das vivências. São grupos formadores de territórios e influenciam na organização espacial, e sobre isso Bonnemaison (2002, p.94) questiona:

[...] faixa de idade, grupo de militantes de um partido político ou de fiéis de uma igreja e outras coisas como essas não podem ser interpretadas como "grupos culturais", isto é, verdadeiras etnias que têm um comportamento próprio, um ser-coletivo que se traduz ao mesmo tempo por uma visão de mundo e por tipos de territorialidade?

Mais além, o autor (p. 94) responde sua própria pergunta quando diz:

Essas "etnias modernas" têm contornos mais fluidos que as etnias tradicionais: elas não têm "território", no sentido como esses existem nas civilizações tradicionais, mas possuem lugares e espaços privilegiados. Elas também possuem códigos, registros, centro de interesses e gostos comuns, uma consciência coletiva quanto aos que estão "do lado de fora", uma maneira de viver seus lazeres, de sair ou não de férias etc.
São essas interações sociais e subjetivas que a fenomenologia atrelada à Geografia Humana se interessa em suas análises espaciais. Considerando alguns aspectos da relação fenomenologia/geografia, coloca-se em evidência a aproximação do pesquisador com o objeto estudado. Partindo desse pressuposto, pode-se dizer que a geografia assume um caráter fenomenológico desde sua episteme, pois os estudos embasados pelo positivismo tinham cunho intencional quando de observava as paisagens e logo, as descreviam. Para a fenomenologia, esse termo "intencionalidade" é diferente do que se realmente entende, pois se expressa no sentido de intenção sobre alguma coisa: significa "consciência de" algo, ou seja, a consciência estaria direcionada para um determinado objeto. Pode expressar também, experiência de algo, o que poderia confirmar o lado fenomenológico da ciência geográfica.

Partindo deste pressuposto, onde "o mundo não é aquilo que eu penso, mas aquilo que eu vivo; estou aberto ao mundo comunico-me indubitavelmente com ele, mas não o possuo, ele é inesgotável" (MERLEAU-PONTY, 1999), os objetos e os fenômenos atrelados a ele, são subsídios da percepção realizada pelo sujeito, que sente o seu mundo ou ainda, seu espaço.

Aliando espaço e escala, dois conceitos fundamentais que se destacam na ciência geográfica, Castro (2001, p. 133) fez referência a Merleau-Ponty, ao destacar que:

\begin{abstract}
A escala é uma projeção do real, mas a realidade continua sendo sua base de constituição, continua nela. Como o real só pode ser aprendido por representação e fragmentação, a escala constitui uma prática, embora não intuitiva e não refletida, de observação e elaboração do mundo. Não espanta a polissemia do termo, sua utilização com significados específicos em diferentes áreas do conhecimento.
\end{abstract}

Nesse sentido, a autora comenta que a continuidade da percepção seria a mudança na escala e ela não depende do recorte gráfico e sim das transformações qualitativas e dinâmicas que apresentam entre os macros e micros espaços, justificando determinados fenômenos. Percebe-se que esta observação está ligada diretamente a ciência geográfica, pois introduz e abarca diversos conceitos utilizados na mesma.

Os embasamentos fenomenológicos na Geografia se estruturam em três pilares fundamentais: espaço, paisagem e lugar o quais estarão diretamente atribuídos ao mundo-vivido, conforme destaca Suertegaray (2005, p. 30):

[...] o espaço é vivido, experienciado. A superfície limitante do espaço experienciado é a paisagem. Finalmente temos o conceito de lugar; este constitui o centro de significados expressando, não só a localização, mas o tipo de experiência com o 
mundo. [...] O mundo vivido é o mundo dos espaços interrelacionais, ou seja, conectam-se no mundo vivido as dimensões natural, social e cultural.

A autora destaca também em suas proposições sobre a fenomenologia dentro da ciência geográfica, quando diz que (...)

[...] a dimensão fenomenológica na Geografia se expressa na ideia/conceito de Geograficidade que significa nossas experiências de vida em relação ao espaço e ao tempo. Assim, temos que a Geograficidade é a nossa forma de se relacionar com as coisas e as pessoas que nos rodeiam. A Geograficidade é a dimensão espacial da experiência humana que se revela necessária desde o nascimento. [...] A noção de tempo e de espaço, portanto, não existem a priori, constituem o sentido dado a nossa existência, e a partir dela, o sentido dado à construção da natureza e da cultura. (p.31)

E se tratando do termo Geograficidade como ponto de partida aos estudos fenomenológicos, não se pode deixar de destacar Edward Relph onde, o autor destaca diferentes interpretações de fenomenologia. Para Relph (1979), o grande foco dos pesquisadores e pensadores humanistas é o mundo vivido. Para ele o mundo vivido é entendido como o mundo das experiências e do sentido que os sujeitos dão a elas no cotidiano. Neste caso, o mundo vivido é um mundo subjetivo. Na concepção de Relph (1970, p.193),

O método fenomenológico é um procedimento para descrever o mundo cotidiano da experiência imediata do homem, incluindo suas ações, lembranças, fantasias e percepções; ele não é um método de análise ou explicação de qualquer mundo objetivo ou racional através do desenvolvimento de hipóteses e teorias prévias.

Neste sentido, a fenomenologia geográfica propõe estudar as experiências concretas do homem e não se fixa a estudar as experiências do conhecimento, ou da vida, tais como se apresentam na história. A tarefa da fenomenologia neste caso é analisar as vivências intencionais da consciência para perceber como se determina o sentido dos fenômenos, pois a razão objetiva se refere a existência humana, independentemente de que possa ser expressa em categorias de quantidade.

Esta realidade é composta por tudo aquilo que se proporciona ao olhar do observador e quando o pesquisador geógrafo vai a campo, é necessário decompor essa observação de acordo com a interpretação do observado, de seus valores, isto é, de sua forma própria de entender essa realidade.

Por fim, ressalta-se a contribuição de Yi-Fu Tuan, geógrafo chinês e grande leitor do filósofo Maurice Merleau-Ponty. É reconhecidamente um dos pesquisadores fun- dadores da tendência humanística e do uso das abordagens fenomenológicas em estudos da ciência geográfica. Suas obras são baseadas em questões sobre o lugar, cuja matriz fenomenológica e existencialista se reafirma como grande subsidiária. Cabe ressaltar que a fenomenologia de Tuan é fundamentalmente baseada por a fenomenologia e o existencialismo, como base filosófica, e a escolha do "lugar" como conceito espacial que mais atendia aos seus propósitos, seriam apropriadas para os estudos propostos por este autor.

Em meados da década de 70 pode-se destacar Tuan e Anne Butttimer como fundamentais contribuidores na busca por uma identidade própria para a geografia humanista. Esses autores foram pioneiros no uso dos conceitos de lugar e de mundo vivido, os quais são associados a uma base teórica fenomenológica, aporte que mais tarde permitiria a identificação de seus trabalhos como humanistas e também, na construção de novas perspectivas metodológicas acerca da geografia.

Nas considerações de Tuan (1982, p. 143), o autor destaca a linha de estudo que traz a fenomenologia como um de seus pressupostos:

[...] a Geografia Humanista procura um entendimento do mundo humano através do estudo das relações das pessoas com a natureza, de seu comportamento geográfico bem como dos seus sentimentos e ideias a respeito do espaço e do lugar.

Para Tuan (1983), o lugar é marcado por três palavras-chave: percepção, experiência e valores. Ele também trás a diferença entre espaço e lugar, onde o espaço pode transformar-se em lugar, na medida em que se atribui a ele valor e significação; o lugar não pode ser compreendido sem ser 'experienciado'. Na concepção de Tuan (1979, p. 387),

[...] o lugar é uma unidade entre outras unidades ligadas pela rede de circulação; [...] o lugar, no entanto, tem mais substância do que nos sugere a palavra localização: ele é uma entidade única, um conjunto 'especial', que tem história e significado. $\mathrm{O}$ lugar encarna as experiências e aspirações das pessoas. O lugar não é só um fato a ser explicado na ampla estrutura do espaço, ele é a realidade a ser esclarecida e compreendida sob a perspectiva das pessoas que lhe dão significado.

Para o autor, espaço e lugar determinam a natureza da ciência geográfica, porém o lugar tem uma maior importância para a tendência humanística, pois para ela constitui um conjunto complexo e simbólico, que pode ser analisado a partir da experiência pessoal de cada indivíduo, ou em um contexto intersubjetivo (experiência em grupo) no espaço. Em sua obra de 1979, Tuan faz uma inferência a visão positivista, afirmando que espaço e lugar, são temas centrais na 
ciência geográfica, sendo que para os positivistas são vistos através do viés organização do espaço e para os geógrafos humanistas, estas duas categorias assumem características diferentes. Porém é importante destacar que os dois entendimentos são de grande valia, pois um pode completar o outro. A importância do "lugar" para a geografia cultural e humanista é, ou deveria ser, óbvia. Como nós funcionais dos espaços, os lugares sujeitam-se as técnicas de análise espacial. (TUAN, 1979).

O mundo vivido é tratado por Buttimer (1982) como uma peça fundamental na relação entre a Geografia e a fenomenologia. Desta forma, ela considera em seus estudos a intersubjetividade, onde destaca:

[...] a intersubjetividade sugere a situação herdada que circunda a vida diária. Pode também ser compreendida como um processo em movimento, pelo qual os indivíduos continuam a criar seus mundos sociais (BUTTIMER, 1982, p. 182).

Neste sentido, pode-se dizer que o modo intersubjetivo permite um diálogo entre a pessoa e a subjetividade do seu mundo, sendo este mundo permeado de valores, de significados e de experiências pessoais. Para a autora, tanto a fenomenologia quanto o existencialismo objetivam-se com a exploração e compreensão dos significados e valores.

O mundo vivido é um dos conceitos importados da fenomenologia para a esta tendência atrelada a Geografia Cultural, e se refere o mundo da vida e da experiência cotidiana, onde busca-se a compreensão da essência das coisas por meio das diversas formas de intencionalidades aplicadas à determinado objeto ou experienciação. Neste sentido, a fenomenologia existencialista, como base filosófica, atrelada a categoria de lugar como conceito espacial que melhor expressa suas pretensões, seriam tomados por Buttimer, Tuan e Relph, expoentes que se empenharam na renovação da geografia cultural, trazendo o reconhecimento da geografia humanista como uma vertente independente da ciência geográfica.

Concluindo, é importante e também necessário um retorno à ontologia da geograficidade e uma análise da importância do lugar para a constituição da própria ciência geográfica. A fenomenologia precisa ser entendida desde sua gênese, para assim, constituir a identidade da mesma como método de abordagem. Dentro do conceito metódico, as técnicas de análises envolvendo a fenomenologia são inúmeras, e as teorias são possíveis de ser aplicados em diversos trabalhos.

\section{CONSIDERAÇÕES FINAIS}

A geografia é "retardatária” em relação às outras ciências, pois ainda usam-se conceitos da dialética para explicar a fenomenologia. Isto é consequência pela chegada das duas abordagens juntas à ciência geográfica e tumultua conceitualmente as explicações dos objetos de estudos. Por isso é importante que o pesquisador ao introduzir a fenomenologia em suas pesquisas, busque os conceitos chaves dentro da ciência filosófica, e delimite até que ponto os embasamentos fenomenológicos são possíveis dentro de suas especificações. A partir da abordagem fenomenológica, existe um leque muito grande e diversificado de contextos que podem ser seguidos entre as mais variadas ciências, incluindo as ciências exatas, pois ela pode ajudar as intencionalidades naturais a esclarecer o que elas buscam, mas nunca substituí-las. Muito pelo contrário, a fenomenologia complementa a atitude originária, pois a filosofia, inclusive na ciência geográfica, complementa a opinião verdadeira e a própria ciência.

Importante salientar que os autores filosóficos que introduziram o conceito de fenomenologia na filosofia, já usavam termos geográficos (espaço, território, lugare até mesmo escala...) na abordagem fenomenológica, porém nem se quer desconfiavam que essas fossem as categorias de análises geográficas e que os geógrafos utilizariam seus pressupostos para criar uma Geografia Humanista, e mais futuramente, atrelar esses estudos na Geografia Humana em geral, incluindo atualmente as temáticas Feministas e Queer, bem como em outros campos dentro da Geografia Física. As elucidações sobre tais termos já eram concretas antes mesmo de a ciência geográfica se apropriar do conceito de fenomenologia, o que permite que ela retorne aos filósofos contemporâneos para entender ainda mais o campo fenomenológico.

Destaca-se ainda que a ideia para a ciência moderna seja a questão do dogma, porém uma verdade comprovada, que pressupõe o método. Neste sentido, as ciências humanas e sociais carregam em suas metodologias um princípio de sistematização, e que não trás rigorosidade em seguir passo a passo a metodologia que se propõe. Neste sentido, seguindo a linha de raciocínio a cerca da abordagem fenomenológica dentro da geografia, o conceito de intencionalidade não aplica-se diretamente à teoria ação humana, mas sim a teoria do conhecimento. Deste modo, a fenomenologia como método de abordagem, é passível de ser incorporada pela ciência geográfica em muitas temáticas, desde estudos na área humana quanto ambiental.

Ela como método de abordagem é um procedimento para descrever o mundo cotidiano da experiência imediata do homem, e isso incluem-se todos seus modos de vivências, como ações, lembranças e percepções. Ela vai valorizar a subjetividade do sujeito, validando a análise experiencial que estará ligada a intencionalidade com que o indivíduo passa a 
ver as coisas ao seu redor, juntamente com o sentimento de pertencimento ao espaço o qual está inserido.

\section{REFERÊNCIAS BIBLIOGRÁFICAS}

BONNEMAISON, Joël. Viagem em torno do território. In: CORRÊA, Roberto Lobato; ROSENDAHL, Zeny (Orgs.). Geografia cultural: um século (3). Rio de Janeiro: EdUERJ, 2002. p. 83-132.

BUTTIMER, Anna. Aprendendo o dinamismo do mundo vivido. In: CHRISTOFOLLETI, Antônio. Perspectiva da Geografia. São Paulo: Difel, 1982.

CASTRO, Iná Elias de. O problema da escala. In: CASTRO, Iná Elias de. GOMES, Paulo César da Costa. CORREAA, Roberto Lobato (Org.). Geografia: conceitos e temas. $3^{\text {a }}$ ed. Rio de Janeiro: Bertrand Brasil, 2001.

GOMES, Paulo César da Costa. Geografia e Modernidade. Rio de Janeiro: Bertrand Brasil, 1996.

HEIDEGGER, Martin. Ser e Tempo. 4. ed. Petrópolis: Vozes, 2009.

MERLEAU-PONTY, Maurice. Fenomenologia da Percepção. São Paulo: Martins Fontes, 1971.

Fenomenologia da Percepção. Tra-

dução Carlos Alberto Ribeiro de Moura. $2^{\circ}$ Ed. São Paulo: Martins Fontes, 1999.

PICKLES, John. Phenomenology, Science and Geography: spatiality and the human sciences. Cambridge: Cambridge University Press, 1985.

RELPH, Edward. An inquiry into the relations between phenomenology and geography. Canadian Geographer. 14 (3) : 193-201., 1970.

As bases Fenomenológicas da Geografia. Rev. Geografia, Rio Claro, vol. 4, n 7, p.1-25, 1979.

SCHUTZ, Alfred. Bases da fenomenologia. In: WAGNER, H. (Org). (1979) Fenomenologia e relações sociais: textos escolhidos de Alfred Schutz. Rio de janeiro: Zahar, 1979.

SCHUTZ, Alfred. Fenomenologia da percepção. Tradu- ção de: Carlos Alberto Ribeiro de Moura. 2a . ed. São Paulo: Martins Fontes, 1999.

SOKOLOWSKI, Robert. Introdução à fenomenologia. Tradução de: Alfredo de O. Moraes. São Paulo: Loyola, 2004.

SUERTEGARAY, Dirce Maria Antunes. Notas sobre Epistemologia da Geografia. Cadernos Geográficos/ Universidade Federal de Santa Catarina. Centro de Filosofia e Ciências Humanas. Departamento de Geociências. n¹, Florianópolis: Imprensa Universitária, 1999.

TUAN, Yi Fu. Space and place: humanistic perspective. In: GALE, S. OLSSON, G. (orgs.). Philosophy in Geography. Dordrecht : Reidel, 1979, p. 387-427.

Geografia Humanística. In: CHRISTOFOLETTI, Antonio (Org.). Perspectivas da Geografia. São Paulo: Difel, 1982. p. 143-164.

Espaço e Lugar: a perspectiva da experiência. Trad. Lívia de Oliveira. São Paulo: Difel, 1983.

Notas de Fim:

1- Técnicas de análise envolvendo o quantitativo são características da Nova Geografia.

2- Terceira geografia é um termo adotado pelo autor do artigo para simbolizar a Geografia Crítica. Para melhor entendimento, estabeleceu também outros dois termos: Segunda geografia para a Nova Geografia e primeira geografia para se referir à Geografia Tradicional.

\section{Correspondência dos autores:}

Taiane Flores do Nascimento

e-mail: tayflores181@yahoo.com.br Benhur Pinós da Costa

e-mail: benpinos@gmail.com

Artigo recebido em: 30/10/2015

Revisado pelos autores em: 04/08/2016

Aceito para publicação em: 25/09/2016 